\title{
Achieving to some outranking relationships between post mining land uses through mined land suitability analysis
}

\author{
H. Soltanmohammadi; *M. Osanloo; B. Rezaei; A. Aghajani Bazzazi \\ Department of Mining Engineering, Amirkabir University of Technology, Tehran, Iran
}

Received 13 April 2008; $\quad$ revised 20 May 2008; $\quad$ accepted 5 July 2008; available online 1 September 2008

\begin{abstract}
Adoption of most suitable post mining land use is a problem with multi-dimensional nature. There are so many factors in this problem which seriously influence on the decision judgments. Therefore, in this study a fiftyattribute framework for mined land suitability analysis including fifty numbers of economical, social, technical and mine site factors developed to be a foundation for this decision making problem. Analysis by an outranking multiattribute decision-making technique, called elimination et choix traduisant la realite method, was taken into consideration because of its clear advantages on the field of mined land suitability analysis as compared with multi-attribute decisionmaking ranking techniques. Analytical hierarchy process method applied to calculate global weights of the attributes through pair wise comparison matrixes. The weights then passed to the elimination et choix traduisant la realit method so that the most efficient post mining land uses could be appointed through comparisons of pair-wise dominance relationships between alternatives. This approach applied to an illustrative example where, final results showed that, there were two non-dominated land-uses for the considered example; industrial and pasture. However by increasing indifference threshold limit, the non-dominated set reduced to a single alternative that was pasture land-use.
\end{abstract}

Key words: Disturbed land, multi-attribute decision-making, analytical hierarchy process, elimination et choix traduisant la realit

\section{INTRODUCTION}

In this paper, a mined land suitability analysis (MLSA) framework containing fifty numbers of leading evaluation attributes and also eight possible groups of post mining land uses for a mined land is provided by reviewing and surveying reclamation practice reports of mines, disturbed lands and many other similar cases. For example, Coppin and Bradshaw, 1982; Chen, et al., 1998; Howat, 2000; Tafi et al., 2006; Carrick and Kruger (2007) have evaluated the factors limiting plant growth on mined soils and mentioned the most serious soil limitations. Some other researchers e.g. Hindle and Grosskopf, 2000; Messing and Hoang, 2001; Hill, 2003; Gizikoff, 2004; Mu (2006) have investigated so many other factors such as topography, climate, environment, society, economy, etc. which arise in land use evaluations of mined or other disturbed lands. Besides, Cairns,1972; Alexander,1998; Errington, 2001; Paschke, et al., 2003; Stellin, et al., 2005; Cao (2007); have focused on special post mining land uses that were exercised in some mine sites. In the proposed MLSA framework, evaluation attributes is categorized into four criteria groups; economical, social, technical, and mine site \*Corresponding Author Email: morteza.osanloo@gmail.com Tel./Fax: +98216 4542929 factors. Each criteria group in turn extends to lower levels consisted of the fifty attributes in a protracted hierarchical structure.

In the last few years, analytical hierarchy process (AHP) method which is a multi-attribute decisionmaking (MADM) technique has been addressed more or less in literature on the field of MLSA process (Uberman and Ostrêga, 2005; Osanloo et al., 2006 and 2007; Bascetin, 2007). That is mainly because using the AHP; evaluation team can systematically compare and determine the global weights of the mined land attributes (Saaty, 1980). However, it has been affirmed that excluding weighting power of this method, it losses advantages against other MADM methods in application on some situations particularly where the problem is proportionately complicated (Eddie et al., 2002). Especially in cases such as the fifty-attribute MLSA framework, where most of the attributes have a qualitative nature, a non-compensatory approach such as; TOPSIS, ELECTRE, PROMETHEE, etc. will be more useful (Hong and Vogel, 1991). Moreover, these methods don't need the decision maker's subjective judgments as much as the AHP does.It can be proved that, outranking MADM techniques such as ELECTRE, 
PROMETHEE, etc. are well suited for conditions that exist in MLSA framework. In a MLSA example, land use alternatives can be very different.

For example, it happens frequently that an alternative has a lot of economic advantages and serious environmental impacts, while another presents the opposite characteristics. In such a case, decision makers may be unable to rank them. These lternatives are thus considered as incomparable and outranking methods are the only methods that can take into account this situation (Joerin et al., 2001).

This paper intends to apply an outranking MADM technique named ELECTRE (Elimination Et Choix Traduisant la Realite) to analysis the provided framework. Before analysis of mined land suitability via ELECTRE method, the AHP method applied to calculate global weights of the attributes through pairwise comparison matrixes. The weights then passed to the ELECTRE method so that the most efficient post mining land uses could be appointed through comparisons of pair-wise dominance relationships between alternatives. This approach applied to an illustrative example, to choose the sufficiently good alternative (s) among fourteen feasible land uses.

\section{MATERIALS AND METHODS}

The MLSA framework

Eight groups of post mining land uses, containing 21 individual land uses which have been exercised in mines of some different countries is provided here (Table 1 ). Some of the adopted land uses had been reported as successful and some had been faced with failure. Closer studies showed that in cases without a mined land suitability analysis process (Alexander, 1998), sometimes obtained result was not acceptable. This made certain, merits of a standardized MLSA framework for post mining land use selection. Thus developing a fifty attribute MLSA framework consisted of economical, social, technical and mine site factors; considered here to make up such a deficiency. The overall goal of the MLSA framework is mined land suitability(Fig. 1). Where, the eight groups of post mining land uses form its alternatives. This framework is built to be solved by an MADM approach. The mine site factors are intrinsic and site-specific attributes that affect the decision. They comprise three groups of attributes namely soil, climate and topography. In general, they include soil's physical properties (SPP), soil's chemical properties (SCP), evaporation (Eva.), frost free days (FFD), precipitation
(Pre.), wind speed (WS), air moisture (AM), temperature (Tem.), hydrology of surface and groundwater (HSG), surface relief (SR), slope(Slop), elevation (Ele.), exposure to sunshine (ES) and physical properties of mine components (PPM).

Technical attributes signify constraints that each one has a tendency to compel the decision maker to an individual post mining land use that is best suited for technological deficiencies arising from that attribute.

The technical factors that were considered here include; shape and size of mined land (SSL), availability of reclamation techniques (ART), closeness to nearest water supply (CNW), market availability (MA), current land use in surrounding area (CLU), prosperity in the mine area (PMA), structural geology (SG), distance from special services (DSS), outlook of future businesses (OFB), environmental contaminations (EC), extreme events potential (EEP), re-using potential of mine facilities (RPM) and landscape quality (LQ).

Economical factors are always of a great importance in MLSA and include attributes such as; maintenance and monitoring costs (MMC), capital costs (CAC), operational costs (OPC), potential absorption (PIA), increase in governmental incomes (IGI), increase in income of local community (IIL) and positive changes in real estate value (CRE). It is clear that these factors because of their uncontrollability have a deterministic role in every MLSA process.

The society i.e. government, community and stakeholders should be consulted during the process of MLSA, especially if a post mining land use is different to the pre-mining land use. Even in some situations for small and isolated mines, the existing land owner and neighbours would constitute the primary groups to be consulted.

Then as well as meeting the other requirements, it is critical that the post mining land use is acceptable to the society. Social factors that were considered here include; effects on immigration to the area (EIA), need to specialist workforces (NSW), positive changes in livelihood quality (CLQ), employment opportunities (EO), serving the public education (SPE), frequency of passing through mine site (FPT), ecological acceptability (EA), tourism attraction (TA), land ownership (LO), proximity of mine site to population centres (PMP), location toward nearest town (LNT), accessibility or road condition (Acc.), mining company policy (MCP), government policy (GP), zoning by-laws (ZB) and consistency with local requirements (CLR). 
Int. J. Environ. Sci. Tech., 5 (4), 535-546, Autumn 2008

Table 1: Some exercised post mining land uses

\begin{tabular}{llll}
\hline Land use types & Exercised post mining land uses & Abbreviations \\
\hline (1) & Agriculture (A) & Arable farmland & A-F \\
& & Garden & A-G \\
& & Pasture or hayland & A-P \\
(2) & Forestry (F) & Nursery & A-N \\
& & Lumber production & F-L \\
(3) $\quad$ Lake or pool (L) & Woodland & F-W \\
& & Shrubs and native forestation & F-S \\
& Aquaculture & L-A \\
(4) $\quad$ Intensive recreation (IR) & Sailing, swimming, etc. & L-S \\
& & Water supply & L-W \\
(5) $\quad$ Non-intensive recreation (NIR) & Sport field & IR-S \\
& & Sailing, swimming or fishing pond, etc. & L-S \\
(6) $\quad$ Construction (CT) & Hunting & IR-H \\
& & Park and open green space & NIR-P \\
& & Museum or exhibition of mining innovations & NIR-M \\
& & Residential & CT-R \\
(7) $\quad$ Conservation (CV) & Commercial (shopping center, etc.) & CT-C \\
(8) & Pit backfilling (B) & Industrial (factory, brick and block making, etc.) & CT-I \\
\end{tabular}

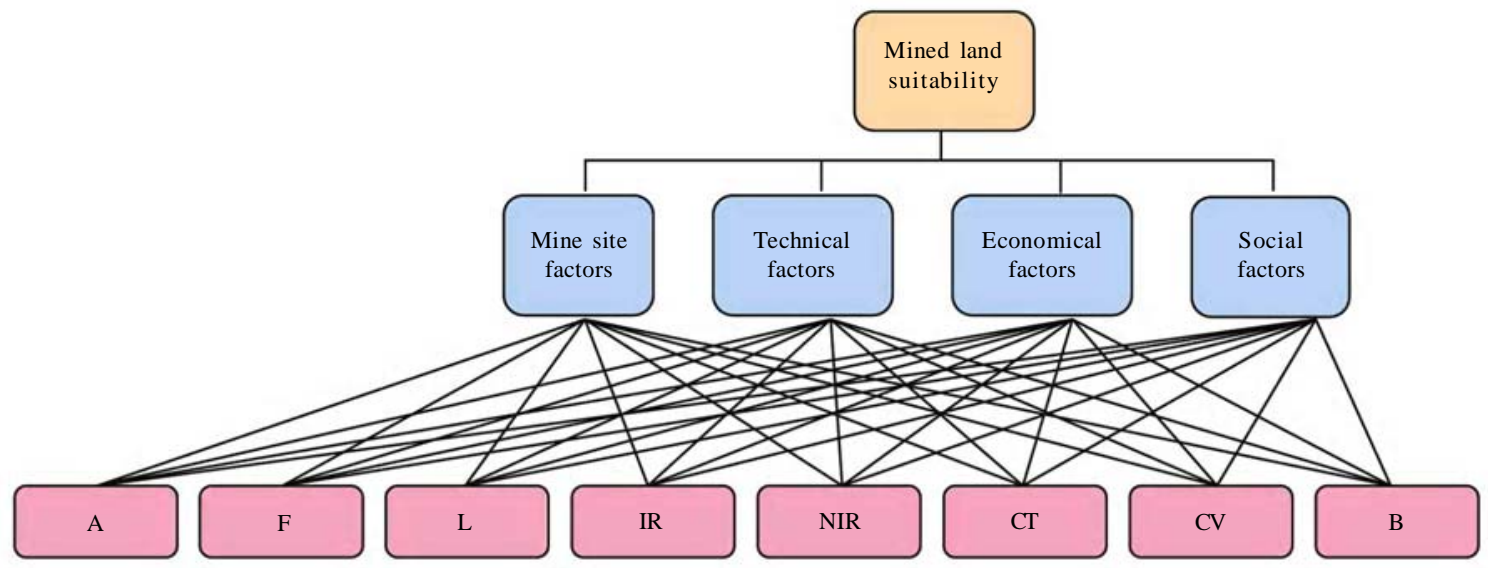

Fig. 1: Hierarchical structure of mined land suitability analysis

The AHP-ELECTRE approach

AHP-ELECTRE approach was applied to analysis an illustrative example which contained the fiftyattribute framework and fourteen feasible competitive post miming land uses including; farmland (A-F), pasture (A-P), nursery (A-N), forestry (F), lake or pool (L), sport field (IR-S), park or open space (NIR-P), residential (CT-R), commercial (CT-C), industrial (CTI), educational (CT-E), a sustainable community (CT$\mathrm{S})$, wildlife habitat (CV-W) and landfill (B). As shown in Fig. 2, these land uses had been ranked by AHPTOPSIS approach in a previous study (Soltanmohammadi et al., 2008). Similar to the previous study, first the performance scores and AHP calculated weights of the attributes were determined by decision maker's subjective judgments. Then, rest of the works turned over to the ELECTRE method. As it has shown in Table 2, for each land use, performance scores were assigned to every fifty attributes. Decision makers have used here the fundamental 1-9 scale defined by Saaty (Saaty, 1990) to assess the performance scores of the attributes.

In the proposed nine-point scale of quantification, score equal to 1 signifies extremely low and score equal to 9 signifies extremely high condition of every attribute against each land use. 
In Table 3, all of the attributes with their assigned performance scores against the land uses are shown.

The rows that are highlighted represent cost attributes and must be minimized in the MLSA process while, the others represent benefit attributes which must be maximized.

\section{Weighting the evaluation attributes using AHP}

AHP quantifies decision-maker's subjective judgements by assigning corresponding numerical values based on the relative importance of the components under consideration. This method is developed by Saaty (1980) and is a powerful decision making methodology in order to determine the priorities among different attributes.

The AHP encompasses six basic steps as summarized as follows:

Step 1: Decompose the decision problem into a hierarchy with a goal at the top, criteria and attributes at levels and sub-levels of and decision alternatives at the bottom of the hierarchy (Fig. 1).

Step 2: The decision matrix, which is based on Saaty's nine-point scale, is constructed. In this context, the assessment of 1 indicates equal importance, 3 moderately more, 5 strongly more, 7 very strongly and 9 indicates extremely more importance. The values of 2, 4, 6, and 8 are allotted to indicate compromise values of importance.

Step 3: The third step involves the comparison in pairs of the elements of the constructed hierarchy. The aim is to set their relative priorities with respect to each of the elements at the next higher level. The pair-wise comparison matrix of $n$ attributes, which is based on the Saaty's 1-9 scale, has the form of Eq. (1):

In the comparison matrix, the elements $a_{i j}$ can be interpreted as the degree of preference of $i$ th attributes over $j$ th attributes.

Step 4: AHP also calculates an inconsistency index (or consistency ratio) to reflect the consistency of decision maker's judgments during the evaluation phase.

$\left[\begin{array}{cccc}w_{1} / w_{1} & w_{1} / w_{2} & \ldots & w_{1} / w_{n} \\ w_{2} / w_{1} & w_{2} / w_{2} & \ldots & w_{2} / w_{n} \\ \vdots & \vdots & \ddots & \vdots \\ w_{n} / w_{1} & w_{n} / w_{2} & \ldots & w_{n} / w_{n}\end{array}\right]=\left[\begin{array}{cccc}a_{11} & a_{12} & \ldots & a_{1 n} \\ a_{21} & a_{22} & \ldots & a_{2 n} \\ \vdots & \vdots & \ddots & \vdots \\ a_{n 1} & a_{n 2} & \ldots & a_{n n}\end{array}\right]$
The inconsistency index in pair-wise comparison matrixes could be calculated with the Eq. (2):

Where, $\lambda_{\max }$ is highest eigenvalue of the pair-wise comparison matrix.

The closer the inconsistency index is to zero, the greater the consistency thus, the relevant index should be lower than 0.10 to accept the AHP results as consistent. If this is not the case, the decision-maker

$C I=\frac{\lambda_{\max }-n}{n-1}$

should go back to Steps 2 and 3 and redo the assessments and comparisons.

Step 5: Before all the calculations of vector of priorities, the comparison matrix has to be normalized. Therefore, each column has to be divided by the sum of entries of the corresponding column. In that way, a normalized matrix is obtained in which the sum of the elements of each column vector is 1 .

Step 6: For the following part, the eigenvalues of this matrix are needed to be calculated which would give the relative weights of attributes.

Such a procedure is common in mathematics; however Expert Choice software has been used here, which is a multi-objective decision support tool. The calculated global weights of the attributes by this software are placed in last column of Table 3. A descending order of these weights has also been illustrated in Fig. 3. According to Eq. (2), an overall inconsistency index of 0.02 motivated the decision makers to accept final results of the AHP method and to import them into the ELECTRE method.

\section{Identification of efficient post mining land uses using ELECTRE method}

The ELECTRE method was originally introduced by Benayoun et al. (1966). Since then Roy (1968); Nijkamp (1977); Roy and Skalka (1984) have developed this method to the present state. in the first step of this methodology, the decision matrix, representing the performance scores $f_{i j}$ of each alternative $j$ with respect to each attribute $i$, is determined (Table 3 ) and then normalized. Next, these normalized performance scores are multiplied with the global attribute weights (Table 3) calculated beforehand with the AHP. This method consists of a pair-wise comparison of alternatives based on the degree to which evaluations of the alternatives and the preference weights confirm or contradict the pair-wise dominance relationships between 
Table 2: Manner of assigning performance scores of the attributes against land-uses

\begin{tabular}{|c|c|c|c|c|c|c|c|c|c|c|}
\hline Extremely low & & & & & & & & & $\rightarrow$ & Extremely high \\
\hline Post mining land uses & 1 & 2 & 3 & 4 & 5 & 6 & 7 & 8 & 9 & Attributes \\
\hline Farmland & & & & & & & & & & Capital costs \\
\hline Industrial & & & & & & & & & & Ecological acceptability \\
\hline
\end{tabular}

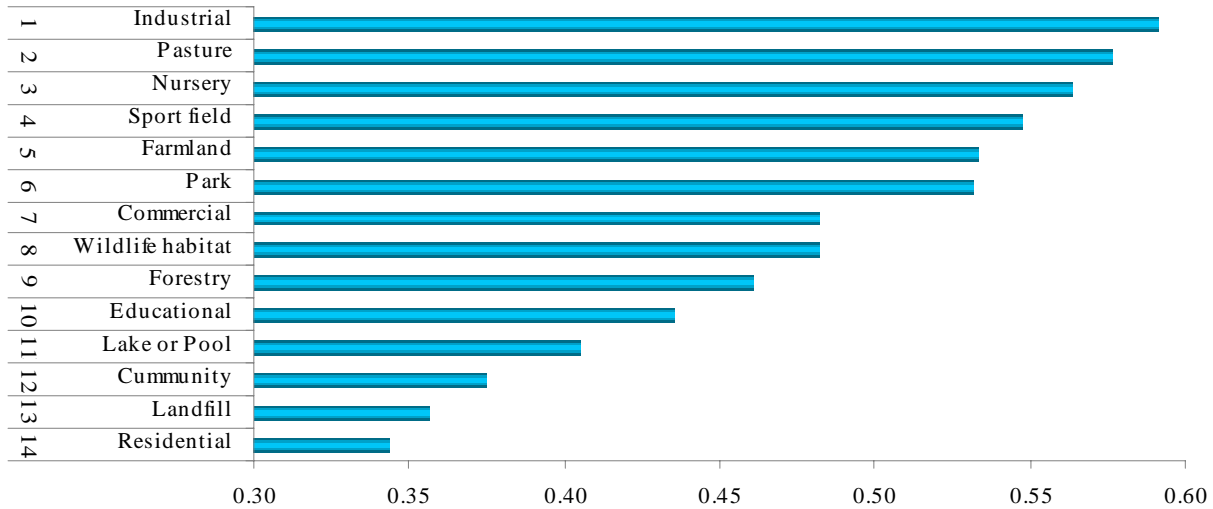

Fig. 2: Descending preference order of the alternative land-uses; analysed using AHP-TOPSIS approach

alternatives. It examines both the degree to which the preference weights are in agreement with pair-wise dominance relationships and the degree to which weighted evaluations differ from each other. These stages are based on a concordance and discordance set; hence this method is also called concordance analysis.

The traditional ELECTRE method takes the following steps:

Step 1: Calculation of normalized rating for each element in the decision matrix. Because the attributes are of benefit and cost types, and different attributes may have different dimensions. Thus, a basic task before multi-attribute decision-making is normalizing the decision matrix.

The normalized values $r_{j i}$ can be calculated as:

Some normalized values of the illustrative example's attributes which are solved using Eq. 3, are shown in Table 4 as a fragmented decision matrix.

$$
r_{j i}=\frac{f_{i j}}{\sqrt{\sum_{j=1}^{J} f_{i j}^{2}}}, i=1, \ldots, n ; j=1
$$

for benefit attributes

$r_{j i}=\frac{1 / f_{i j}}{\sqrt{\sum_{j=1}^{J}\left(1 / f_{i j}\right)^{2}}}, i=1, \ldots, n ; j=1$

for cost attributes
Step 2: Calculation of weighted normalized decision matrix. The AHP calculated weights used as a weight vector $w_{i}$ and is multiplied with vector of the normalized decision matrix (Table 5). The weighted normalized decision matrix $v_{j i}$ is calculated by Eq. 4 :

$v_{j i}=r_{j i} \times w_{i}=\left(\begin{array}{ccc}r_{11} w_{1} & \ldots & r_{1 n} w_{n} \\ \vdots & \ddots & \vdots \\ r_{J 1} w_{1} & \ldots & r_{J n} w_{n}\end{array}\right)$

$i=1, \ldots, n ; j=1, \ldots, J$.

Step 3: Determination of concordance and discordance sets. For each pair of alternatives $k$ and $l,(k, l=1,2, \ldots$, $\left.J ; k^{\text {" }} l\right)$ the set of evaluation attributes $n=\{i \mid i=1$, 2, $\ldots, n\}$ is divided into two distinct sets; the concordance set $C_{k l}$ and discordance set $D_{k l}$, the elements in $C_{k l}$ are all attributes for which $v_{k i} \mathrm{e}$ " $v_{l i}$, the elements in $D_{k l}$ are all attributes for which $v_{l i} \mathrm{e}$ " $v_{k i}$. In other words;

$C_{k l}=\left\{i \mid v_{k i} \geq v_{l i}\right\}$.

The complementary subset is called the discordant set, which is;

$D_{k l}=\left\{i \mid v_{l i} \geq v_{k i}\right\}$

Concordance and discordance attribute sets of the fragmented decision matrix in Table 5, according to Eq. 
(5) and Eq. (6) are as follows; whereas $k$ is farmland (A-F):

$$
\begin{aligned}
& C\left(A_{-} F\right)\left(A_{-} P\right)=\{M M C, P I A, \ldots, E S\}=D(A-P)(A-F) \\
& D\left(A_{-} F\right)\left(A_{-} P\right)=\left\{\begin{array}{l}
C A C, \text { OPC }, \text { PIA, }, . ., \text { Slop }, \\
\text { Ele, ES }, \text { PPM }
\end{array}\right\}= \\
& C(A-P)(A-F) \\
& C\left(A_{-} F\right)\left(A_{-} N\right)=\{O P C, \ldots, E S\}=D(A-N)(A-F) \\
& D\left(A_{-} F\right)\left(A_{-} N\right)=\left\{\begin{array}{l}
M M C, C A C, \text { OPC }, P I A, \ldots, \text { Slop }, \\
\text { Ele }, E S, P P M
\end{array}\right\}= \\
& C(A-N)(A-F)
\end{aligned}
$$$$
C\left(A_{-} F\right)\left(I R_{-} S\right)=\{C A C, O P C, \ldots, \text { Ele }, E S\}=
$$$$
D(I R-S)(A-F)
$$$$
D\left(A_{-} F\right)\left(I R_{-} S\right)=\left\{\begin{array}{l}
M M C, P I A, \ldots, \text { Slop }, \\
E S, P P M
\end{array}\right\}=
$$$$
C(I R-S)(A-F)
$$$$
C\left(A_{-} F\right)\left(N I R_{-} P\right)=\{C A C, O P C, \ldots, E S\}=
$$$$
D(N I R-P)(A-F)
$$$$
D\left(A_{-} F\right)\left(N_{R}{ }_{-} P\right)=\left\{\begin{array}{l}
M M C, C A C, O P C, P I A, \ldots, \\
\text { Slop , Ele }, E S, P P M
\end{array}\right\}=
$$$$
C(N I R-P)(A-F)
$$

$$
\begin{aligned}
& C\left(A_{-} F\right)\left(C T_{-} I\right)=\{C A C, O P C, \ldots, E S\}= \\
& D(C T-I)(A-F) \\
& D\left(A_{-} F\right)\left(C T_{-} I\right)=\{M M C, P I A, \ldots, \text { Slop, Ele, } P P M\}= \\
& \quad C(C T-I)(A-F)
\end{aligned}
$$

Step 4: Calculating the concordance indices, and establishing a concordance matrix. The concordance index $I_{k l}$ between alternatives $k$ and $l$ is defined as;

$$
I_{k l}=\sum_{i \in C_{k l}} w_{i}
$$

The concordance index $I_{k l}$ reflects the relative importance of alternative $k$ with respect to alternative $l$. The successive values of the concordance indices $I_{k l}$ $(k, l=1,2, \ldots, J ; k$ “" $l)$ form the concordance matrix $I$ of $J \times J$

$I=\left(\begin{array}{cccc}- & I_{12} & \ldots & I_{1 J} \\ I_{21} & - & & I_{2 J} \\ \vdots & & \ddots & \vdots \\ I_{J 1} & I_{J 2} & \cdots & -\end{array}\right)_{J \times J}$

\begin{tabular}{|c|c|c|c|c|c|c|c|c|c|c|c|c|c|c|c|c|}
\hline$i$ & $j$ & $A-F$ & $A-P$ & $A-N$ & $F$ & $L$ & $\begin{array}{c}I R- \\
S \\
\end{array}$ & $\begin{array}{c}I R- \\
P\end{array}$ & $\begin{array}{c}C T- \\
R \\
\end{array}$ & $\begin{array}{c}C T- \\
C\end{array}$ & $\begin{array}{c}C T- \\
I\end{array}$ & $\begin{array}{c}C T- \\
E\end{array}$ & $\begin{array}{c}C T- \\
S\end{array}$ & $\begin{array}{c}C V- \\
W\end{array}$ & $B$ & Weights \\
\hline 1 & MMC & 6 & 7 & 5 & 8 & 8 & 2 & 5 & 6 & 4 & 1 & 4 & 7 & 8 & 8 & 0.040597 \\
\hline 2 & CAC & 4 & 2 & 1 & 3 & 1 & 5 & 4 & 6 & 7 & 7 & 6 & 8 & 3 & 0 & 0.033831 \\
\hline 4 & PIA & 1 & 1 & 6 & 0 & 7 & 7 & 6 & 3 & 7 & 8 & 3 & 2 & 8 & 1 & 0.028268 \\
\hline 5 & IGI & 6 & 6 & 4 & 7 & 7 & 7 & 0 & 2 & 7 & 8 & 1 & 3 & 5 & 3 & 0.022741 \\
\hline 48 & Ele & 4 & 2 & 2 & 2 & 7 & 8 & 2 & 4 & 4 & 2 & 4 & 5 & 1 & 7 & 0.008982 \\
\hline 49 & ES & 7 & 7 & 7 & 7 & 6 & 7 & 7 & 4 & 4 & 4 & 4 & 7 & 7 & 4 & 0.009999 \\
\hline 50 & PPM & 8 & 6 & 4 & 5 & 1 & 1 & 1 & 7 & 6 & 1 & 7 & 6 & 7 & 2 & 0.021648 \\
\hline
\end{tabular}

The concordance matrix of proposed example established using Eq. (7) and Eq. (8) is shown in form of Table 6.

Step 5: Calculating the discordance indices, and establishing a discordance matrix. The discordance index $N I_{k l}$ between alternatives $k$ and $l$ can be calculated by formula;

Similar to the previous step, the discordance matrix can be set up as;

Table 3: Part of performance scores assigned to the considered example and calculated attributes weights 


$$
N I_{k l}=\frac{\operatorname{Max}\left|v_{k i}-v_{l i}\right|, i \in D_{k l}}{\operatorname{Max}\left|v_{k i}-v_{l i}\right|, i=1,2, \ldots, n}
$$

The discordance matrix of proposed example established using Eq. (9) and Eq. (10) is shown in form

$$
N I=\left(\begin{array}{cccc}
- & N I_{12} & \cdots & N I_{1 J} \\
N I_{21} & - & & N I_{2 J} \\
\vdots & & \ddots & \vdots \\
N I_{J 1} & N I_{J 2} & \cdots & -
\end{array}\right)_{J \times J}
$$

of Table 7.

Step 6: Determination of the concordance dominance matrix. This matrix can be calculated by concordance index and a parameter called preference threshold limit (a), the parameter $a$ can be calculated as;

Then through comparing all elements in concordance matrix and the value of $a$, the concordance dominance

$$
\alpha=\frac{1}{J(J-1)} \sum_{\substack{k=1 l=1 \\ k \neq l l \neq k}}^{J} \sum_{k l}
$$

matrix $G$ can be established, the elements of which are defined as;

The value of preference threshold limit $a$ for the given example was calculated by Eq. (11);

$$
\left\{\begin{array}{l}
g_{k l}=1, \quad I_{k l} \geq \alpha \\
g_{k l}=0, \quad I_{k l}<\alpha
\end{array}\right.
$$

And Through comparing elements in concordance matrix (Table 6) with the value of $a$, the concordance

$$
\begin{gathered}
\alpha=\frac{1}{14 \times 13} \sum_{\substack{k=1 \\
k \neq l=1 \\
k \neq l}}^{14} \sum_{l \neq k}^{14} I_{k l}=0.564 \\
\text {. }
\end{gathered}
$$

dominance matrix was established using Eq. (12); this matrix is shown in Table 8 .

Step 7: Determination of the discordance dominance matrix. This matrix can be calculated by discordance index and a parameter called indifference threshold limit (a), the parameter $a$ can be calculated as;

Then through comparing all elements in concordance matrix and the value of $a$, the discordance dominance

$$
\begin{aligned}
& \beta=\frac{1}{J(J-1)} \sum_{k=1}^{J} \sum_{l=1}^{J} N I_{k l} \\
& k \neq l l \neq k
\end{aligned}
$$

matrix $H$ can be established, the elements of which are defined as;

The value of indifference threshold limit $a$ for the given example was calculated by Eq. (13);

$$
\begin{cases}h_{k l}=1, & I_{k l} \leq \beta \\ h_{k l}=0, & I_{k l}>\beta\end{cases}
$$

And Through comparing elements in discordance matrix (Table 7) with the value of $a$, the discordance

$$
\begin{aligned}
& \beta=\frac{1}{14 \times 13} \sum_{k=1}^{14} \sum_{l=1}^{14} N I_{k l}=0.874 \\
& k \neq l l \neq k
\end{aligned}
$$

dominance matrix $H$ established using Eq. (14); this matrix is shown in Table 9.

Step 8: Determination of the aggregate dominance matrix (Table 10). The aggregate dominance matrix $E=\left[e_{k l}\right]_{J \times J}$ is established by $H$ and $G$ matrixes. Its elements can be calculated as;

Step 9: Elimination of the inferior alternatives. While the outranking relationship has been constructed,

$e_{k l}=h_{k l} \cdot g_{k l}$

the less favourable alternatives can be eliminated, and as a result; non-inferior solution set can be obtained. The dominated alternatives can be easily identified in the $E$ matrix, in such a manner that, any column(s) which have an element of 1 is simply eliminated.

Therefore, existence of element 1 in a cell $(l, k)$ of the aggregate dominance matrix means that, the present alternative in the row $l$ is preferred to the present alternative in the column $k$.

In ELECTRE algorithm, the final result is not acceptable unless an appropriate outranking relationship is established. In this manner, the alternative set $J$ is reduced to a smaller subset $J$. The elements in $J$ is preferred to other alternatives. If $J$ is small enough, then the process finishes. Or else, by 
changing the thresholds $a$ and $a$, the number of nondominated alternatives can be reduced.

However, while the symbol > signifies preference; for the given example the following outrankin grelationships can be achieved from Table 10:

Farmland > residential, educational, community, landfill

Pasture $>$ farmland, nursery, forestry, lake, sport field, park, residential, commercial, educational, community, landfill

Nursery > forestry, lake, sport field, park, residential, commercial, wildlife habitat, landfill
Forestry $>$ residential, community

Sport field $>$ park, residential, commercial, landfill

Park $>$ residential, wildlife habitat, landfill

Residential $>$ landfill

Commercial $>$ residential

Industrial $>$ residential, commercial, educational

Educational > residential, commercial, community, landfill

Wildlife habitat $>$ residential

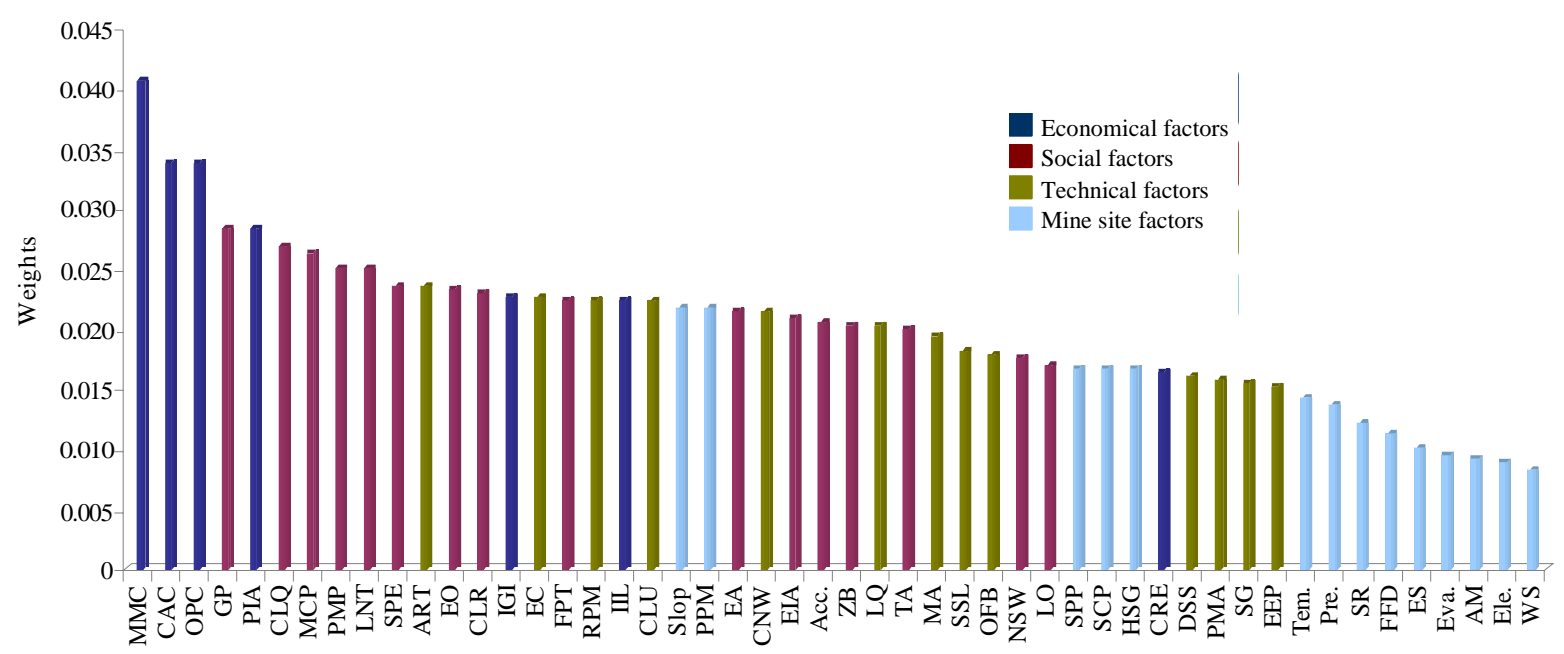

Parameters

Fig. 3: Global weights of the evaluation attributes calculated, using AHP method

Table 4: Normalized values in a fragmented decision matrix

\begin{tabular}{|c|c|c|c|c|c|c|c|c|}
\hline & MMC & CAC & OPC & PIA & Slop & Ele. & ES & PPM \\
\hline Farmland & 0.16609 & 0.23133 & 0.31009 & 0.08891 & 0.09265 & 0.22942 & 0.30544 & 0.00118 \\
\hline Pasture & 0.08305 & 0.34699 & 0.43412 & 0.08891 & 0.32427 & 0.34412 & 0.30544 & 0.12127 \\
\hline Nursery & 0.24914 & 0.40482 & 0.31009 & 0.31119 & 0.37059 & 0.34412 & 0.30544 & 0.24254 \\
\hline Park & 0.24914 & 0.23133 & 0.31009 & 0.31119 & 0.32427 & 0.34412 & 0.30544 & 0.42444 \\
\hline Industrial & 0.58132 & 0.05783 & 0.06202 & 0.40010 & 0.32427 & 0.34412 & 0.19090 & 0.42444 \\
\hline Weights & 0.04060 & 0.03383 & 0.03383 & 0.02827 & 0.02167 & 0.00898 & 0.01000 & 0.02165 \\
\hline
\end{tabular}

!

Table 5: Weighted normalized values in a fragmented decision matrix

\begin{tabular}{lcccccccc}
\hline & MMC & CAC & OPC & PIA & Slop & Ele. & ES & PPM \\
\hline Farmland & 0.00674 & 0.00783 & 0.01049 & 0.00251 & 0.00201 & 0.00206 & 0.00305 & 0.00000 \\
Pasture & 0.00337 & 0.01174 & 0.01469 & 0.00251 & 0.00703 & 0.00309 & 0.00305 & 0.00263 \\
Nursery & 0.01011 & 0.01370 & 0.01049 & 0.00880 & 0.00803 & 0.00309 & 0.00305 & 0.00525 \\
Sport field & 0.02023 & 0.00587 & 0.00629 & 0.01005 & 0.00803 & 0.00000 & 0.00305 & 0.00919 \\
Park & 0.01011 & 0.00783 & 0.01049 & 0.00880 & 0.00703 & 0.00309 & 0.00305 & 0.00919 \\
Industrial & 0.02360 & 0.00196 & 0.00210 & 0.01131 & 0.00703 & 0.00309 & 0.00191 & 0.00919 \\
Weights & 0.04060 & 0.03383 & 0.03383 & 0.02827 & 0.02167 & 0.00898 & 0.01000 & 0.02165 \\
\hline
\end{tabular}


Table 6: Concordance matrix of fourteen post mining land uses

\begin{tabular}{|c|c|c|c|c|c|c|c|c|c|c|c|c|c|}
\hline --- & 0.490 & 0.618 & 0.594 & 0.657 & 0.566 & 0.516 & 0.791 & 0.601 & 0.589 & 0.723 & 0.712 & 0.577 & 0.755 \\
\hline 0.755 & --- & 0.649 & 0.658 & 0.738 & 0.577 & 0.647 & 0.774 & 0.706 & 0.633 & 0.754 & 0.795 & 0.654 & 0.870 \\
\hline 0.543 & 0.495 & --- & 0.638 & 0.701 & 0.573 & 0.571 & 0.810 & 0.638 & 0.549 & 0.701 & 0.765 & 0.576 & 0.801 \\
\hline 0.476 & 0.474 & 0.460 & --- & 0.747 & 0.509 & 0.558 & 0.678 & 0.552 & 0.465 & 0.674 & 0.649 & 0.749 & 0.741 \\
\hline 0.405 & 0.316 & 0.442 & 0.442 & --- & 0.504 & 0.434 & 0.476 & 0.516 & 0.324 & 0.502 & 0.486 & 0.456 & 0.678 \\
\hline 0.494 & 0.501 & 0.577 & 0.626 & 0.734 & --- & 0.615 & 0.834 & 0.732 & 0.484 & 0.787 & 0.756 & 0.608 & 0.822 \\
\hline 0.663 & 0.585 & 0.628 & 0.653 & 0.702 & 0.605 & --- & 0.740 & 0.616 & 0.478 & 0.707 & 0.776 & 0.642 & 0.786 \\
\hline 0.310 & 0.311 & 0.247 & 0.453 & 0.581 & 0.309 & 0.289 & --- & 0.399 & 0.318 & 0.643 & 0.618 & 0.443 & 0.671 \\
\hline 0.537 & 0.462 & 0.456 & 0.569 & 0.632 & 0.477 & 0.508 & 0.786 & --- & 0.445 & 0.718 & 0.721 & 0.566 & 0.829 \\
\hline 0.555 & 0.536 & 0.612 & 0.606 & 0.721 & 0.617 & 0.653 & 0.736 & 0.730 & --- & 0.679 & 0.751 & 0.594 & 0.896 \\
\hline 0.401 & 0.380 & 0.377 & 0.518 & 0.571 & 0.413 & 0.430 & 0.795 & 0.610 & 0.402 & --- & 0.702 & 0.523 & 0.731 \\
\hline 0.352 & 0.399 & 0.353 & 0.406 & 0.591 & 0.310 & 0.353 & 0.547 & 0.394 & 0.298 & 0.485 & --- & 0.446 & 0.688 \\
\hline 0.523 & 0.500 & 0.474 & 0.539 & 0.702 & 0.550 & 0.559 & 0.647 & 0.489 & 0.481 & 0.563 & 0.641 & --- & 0.730 \\
\hline 0.289 & 0.192 & 0.230 & 0.333 & 0.485 & 0.246 & 0.276 & 0.491 & 0.323 & 0.221 & 0.386 & 0.424 & 0.333 & --- \\
\hline
\end{tabular}

Table 7: Discordance matrix of fourteen post mining land uses

\begin{tabular}{|ccccccccccccccc}
\hline--- & 1.000 & 1.000 & 1.000 & 0.875 & 1.000 & 0.875 & 0.625 & 1.000 & 0.875 & 0.857 & 0.500 & 1.000 & 0.750 \\
0.800 & --- & 0.750 & 0.750 & 0.750 & 0.750 & 0.750 & 0.625 & 0.857 & 0.875 & 0.857 & 0.625 & 1.000 & 0.750 \\
0.857 & 1.000 & --- & 0.714 & 0.625 & 0.833 & 0.714 & 0.750 & 0.714 & 1.000 & 1.000 & 0.875 & 0.714 & 0.375 \\
1.000 & 1.000 & 1.000 & --- & 1.000 & 0.875 & 1.000 & 0.750 & 0.875 & 1.000 & 0.875 & 0.750 & 1.000 & 0.875 \\
1.000 & 1.000 & 1.000 & 1.000 & --- & 1.000 & 1.000 & 1.000 & 1.000 & 1.000 & 1.000 & 1.000 & 1.000 & 1.000 \\
0.857 & 1.000 & 1.000 & 1.000 & 0.875 & --- & 0.857 & 0.625 & 0.857 & 1.000 & 1.000 & 0.875 & 1.000 & 0.625 \\
1.000 & 1.000 & 1.000 & 1.000 & 0.875 & 1.000 & --- & 0.750 & 1.000 & 1.000 & 1.000 & 0.875 & 0.750 & 0.500 \\
1.000 & 1.000 & 1.000 & 1.000 & 1.000 & 1.000 & 1.000 & --- & 1.000 & 1.000 & 1.000 & 1.000 & 1.000 & 0.750 \\
1.000 & 1.000 & 1.000 & 1.000 & 0.875 & 1.000 & 1.000 & 0.714 & --- & 1.000 & 1.000 & 1.000 & 1.000 & 0.875 \\
1.000 & 1.000 & 1.000 & 1.000 & 1.000 & 1.000 & 1.000 & 0.571 & 0.857 & --- & 0.857 & 0.875 & 1.000 & 1.000 \\
1.000 & 1.000 & 1.000 & 1.000 & 0.875 & 0.875 & 0.875 & 0.750 & 0.750 & 1.000 & --- & 0.625 & 1.000 & 0.750 \\
1.000 & 1.000 & 1.000 & 1.000 & 0.875 & 1.000 & 1.000 & 0.833 & 1.000 & 1.000 & 1.000 & -- & 1.000 & 1.000 \\
0.857 & 1.000 & 1.000 & 0.875 & 0.875 & 1.000 & 1.000 & 0.750 & 0.875 & 1.000 & 0.750 & 1.000 & --- & 1.000 \\
1.000 & 1.000 & 1.000 & 1.000 & 1.000 & 1.000 & 1.000 & 1.000 & 1.000 & 1.000 & 1.000 & 1.000 & 1.000 & --- \\
\hline
\end{tabular}

Table 8: Concordance dominance matrix of fourteen post mining land uses

\begin{tabular}{|c|c|c|c|c|c|c|c|c|c|c|c|c|c|c|}
\hline$A-F$ & --- & 0 & 1 & 1 & 1 & 1 & 0 & 1 & 1 & 1 & 1 & 1 & 1 & 1 \\
\hline A-P & 1 & --- & 1 & 1 & 1 & 1 & 1 & 1 & 1 & 1 & 1 & 1 & 1 & 1 \\
\hline$A-N$ & 0 & 0 & --- & 1 & 1 & 1 & 1 & 1 & 1 & 0 & 1 & 1 & 1 & 1 \\
\hline F & 0 & 0 & 0 & --- & 1 & 0 & 0 & 1 & 0 & 0 & 1 & 1 & 1 & 1 \\
\hline IR-S & 0 & 0 & 1 & 1 & 1 & --- & 1 & 1 & 1 & 0 & 1 & 1 & 1 & 1 \\
\hline NIR-P & 1 & 1 & 1 & 1 & 1 & 1 & --- & 1 & 1 & 0 & 1 & 1 & 1 & 1 \\
\hline CT-I & 0 & 0 & 1 & 1 & 1 & 1 & 1 & 1 & 1 & --- & 1 & 1 & 1 & 1 \\
\hline CT-E & 0 & 0 & 0 & 0 & 1 & 0 & 0 & 1 & 1 & 0 & --- & 1 & 0 & 1 \\
\hline CT-S & 0 & 0 & 0 & 0 & 1 & 0 & 0 & 0 & 0 & 0 & 0 & --- & 0 & 1 \\
\hline CV-W & 0 & 0 & 0 & 0 & 1 & 0 & 0 & 1 & 0 & 0 & 0 & 1 & --- & 1 \\
\hline B & 0 & 0 & 0 & 0 & 0 & 0 & 0 & 0 & 0 & 0 & 0 & 0 & 0 & --- \\
\hline
\end{tabular}


H. Soltanmohammadi et al.

\begin{tabular}{|c|c|c|c|c|c|c|c|c|c|c|c|c|c|c|}
\hline \multirow[b]{2}{*}{ A-F } & \multirow[b]{2}{*}{--- } & \multirow[b]{2}{*}{0} & & & & & & & & & & & & \multirow[b]{2}{*}{1} \\
\hline & & & 0 & 0 & 0 & 0 & 0 & 1 & 0 & 0 & 1 & 1 & 0 & \\
\hline A-P & 1 & --- & 1 & 1 & 1 & 1 & 1 & 1 & 1 & 0 & 1 & 1 & 0 & 1 \\
\hline A-N & 1 & 0 & --- & 1 & 1 & 1 & 1 & 1 & 1 & 0 & 0 & 0 & 1 & 1 \\
\hline $\mathrm{F}$ & 0 & 0 & 0 & --- & 0 & 0 & 0 & 1 & 0 & 0 & 0 & 1 & 0 & 0 \\
\hline $\mathrm{L}$ & 0 & 0 & 0 & 0 & --- & 0 & 0 & 0 & 0 & 0 & 0 & 0 & 0 & 0 \\
\hline IR-S & 1 & 0 & 0 & 0 & 0 & --- & 1 & 1 & 1 & 0 & 0 & 0 & 0 & 1 \\
\hline NIR-P & 0 & 0 & 0 & 0 & 0 & 0 & --- & 1 & 0 & 0 & 0 & 0 & 1 & 1 \\
\hline CT-R & 0 & 0 & 0 & 0 & 0 & 0 & 0 & --- & 0 & 0 & 0 & 0 & 0 & 1 \\
\hline CT-C & 0 & 0 & 0 & 0 & 0 & 0 & 0 & 1 & --- & 0 & 0 & 0 & 0 & 0 \\
\hline CT-I & 0 & 0 & 0 & 0 & 0 & 0 & 0 & 1 & 1 & --- & 1 & 0 & 0 & 0 \\
\hline CT-E & 0 & 0 & 0 & 0 & 0 & 0 & 0 & 1 & 1 & 0 & --- & 1 & 0 & 1 \\
\hline CT-S & 0 & 0 & 0 & 0 & 0 & 0 & 0 & 1 & 0 & 0 & 0 & --- & 0 & 1 \\
\hline CV-W & 1 & 0 & 0 & 0 & 0 & 0 & 0 & 1 & 0 & 0 & 1 & 0 & --- & 1 \\
\hline B & 0 & 0 & 0 & 0 & 0 & 0 & 0 & 0 & 0 & 0 & 0 & 0 & 0 & --- \\
\hline
\end{tabular}

Table 10: Aggregate dominance matrix of fourteen post mining land uses

\begin{tabular}{|c|c|c|c|c|c|c|c|c|c|c|c|c|c|}
\hline A-F & A-P & A-N & $\mathrm{F}$ & $\mathrm{L}$ & IR-S & NIR-P & CT-R & CT-C & CT-I & CT-E & CT-S & CV-W & B \\
\hline 0 & 0 & 0 & 0 & 0 & 0 & 0 & 1 & 0 & 0 & 1 & 1 & 0 & 1 \\
\hline 1 & 0 & 1 & 1 & 1 & 1 & 1 & 1 & 1 & 0 & 1 & 1 & 0 & 1 \\
\hline 0 & 0 & 0 & 1 & 1 & 1 & 1 & 1 & 1 & 0 & 0 & 0 & 1 & 1 \\
\hline 0 & 0 & 0 & 0 & 0 & 0 & 0 & 1 & 0 & 0 & 0 & 1 & 0 & 0 \\
\hline 0 & 0 & 0 & 0 & 0 & 0 & 0 & 0 & 0 & 0 & 0 & 0 & 0 & 0 \\
\hline 0 & 0 & 0 & 0 & 0 & 0 & 1 & 1 & 1 & 0 & 0 & 0 & 0 & 1 \\
\hline 0 & 0 & 0 & 0 & 0 & 0 & 0 & 1 & 0 & 0 & 0 & 0 & 1 & 1 \\
\hline 0 & 0 & 0 & 0 & 0 & 0 & 0 & 0 & 0 & 0 & 0 & 0 & 0 & 1 \\
\hline 0 & 0 & 0 & 0 & 0 & 0 & 0 & 1 & 0 & 0 & 0 & 0 & 0 & 0 \\
\hline 0 & 0 & 0 & 0 & 0 & 0 & 0 & 1 & 1 & 0 & 1 & 0 & 0 & 0 \\
\hline 0 & 0 & 0 & 0 & 0 & 0 & 0 & 1 & 1 & 0 & 0 & 1 & 0 & 1 \\
\hline 0 & 0 & 0 & 0 & 0 & 0 & 0 & 0 & 0 & 0 & 0 & 0 & 0 & 0 \\
\hline 0 & 0 & 0 & 0 & 0 & 0 & 0 & 1 & 0 & 0 & 0 & 0 & 0 & 0 \\
\hline 0 & 0 & 0 & 0 & 0 & 0 & 0 & 0 & 0 & 0 & 0 & 0 & 0 & 0 \\
\hline
\end{tabular}

\section{RESULTS AND DISCUSSION}

As it can be seen in Table 10, two columns of the aggregate dominance matrix which are highlighted don't have any element of 1 and can be identified as nondominated alternatives. These alternatives are concluded as efficient alternatives and include; pasture (A-P) and industrial (CT-I) post mining land uses. Paying attention to the final result of a TOPSIS ranking approach (Fig. 2), the above alternatives were of high preference in that method too. Secondly, Table 10 shows that, landfill (B), sustainable community (CT$\mathrm{S})$, and lake or pool (L) post mining land uses, which are located in highlighted rows, don't have any element of 1 and can be concluded as worst alternatives. This latter, also substantiate the previous approach (Fig. 2) well. Thus, existence of a great harmony between results of two applied approaches; properly demonstrate that, the procedure to solve the proposed MLSA fifty-attribute framework is quite valid for the given example.

However, in order to reduce the members of nondominated subset $J$ to a single post mining land use, the preference ( $a$ ) and indifference ( $a$ ) threshold limits have been changed. Results showed that when $a$ value remains constant, a very small increasing of $a$ value to 0.875 will reduce $J$ members to a single superior alternative that is pasture land-use. Whereas, this 
alternative was placed in second standing, according to the TOPSIS approach. This dissimilarity between the results of two applied approaches can be justified by (1); the different algorithms that the methods take into service and (2); equal desirability of the alternatives for decision makers. There is not any evidence anyhow, to persuade acceptation of just one approach and refusing another. This means that, further research is still necessary to facilitate decision making about applying more appropriate MADM tools on the field of MLSA. However, this study showed using the proposed AHP-ELECTRE algorithm; the outranking relationships between alternatives and in this way, the non-dominated set of land-use alternatives by any other alternatives can be identified. Also, according to this approach the worst alternatives for a given example can be recognized as well. The outranking result obtained by ELECTRE is more useful in comparison with the TOPSIS ranking result, because contrary to the TOPSIS method this approach can reveal any incomparability between the alternatives. This advantageous is more valuable especially when the numbers of possible alternatives are very high.

\section{REFERENCES}

Alexander, M. J., (1998). The effectiveness of small-scale irrigated agriculture in the reclamation of mine land soils on the Jos Plateau of Nigeria, Land Degrad. Dev., 7 (1), $77-85$.

Bascetin, A., (2007). A decision support system using analytical hierarchy process for the optimal environmental reclamation of an open-pit mine, Environ. Geol., 52 (4), 663-672.

Benayoun, R.; Roy, B.; Sussman B., (1966). ELECTRE: Une méthode pour guider le choix en présence de points de vue multiples, Note de travail 49, SEMA-METRA International Direction Scientifique.

Cairns, J., (1972). Ecological considerations in reclaiming surface mined lands, Miner. Environ., 1 (3), 83-89

Cao, X., (2007). Regulating mine land reclamation in developing countries: The case of China, Land Use Policy, 24 (2), 472-483.

Carrick, P. J.; Kruger, R., (2007). Restoring degraded landscapes in lowland Namaqualand: Lessons from the mining experience and from regional ecological dynamics, J. Arid Environ., 70 (4), 767-781.

Chen, H.; Zheng, C.; Zhu, Y., (1999). Phosphorus: A limiting factor for restoration of soil fertility in a newly reclaimed coal mined site in Xuzhou, China, Land Degrad. Dev., 9 (2), 115-121.

Coppin, N. J.; Bradshaw, A. D., (1982). Quarry reclamation; The establishment of vegetation in quarries and open pit non-metal mines, Mining Journal Books Ltd., London, England, 18-25.
Eddie, W. L.; Heng, L.; Danny, C. K., (2002). Analytical hierarchy process (AHP); A defective tool when used improperly, Meas. Bus. Excellence, 6 (4), 33-37.

Errington, J. C., (2001). Mine reclamation in British Columbia, 25 years of progress, 25 th. Annual British Columbia Mine Reclamation Symposium, Campbell River, BC.

Gizikoff, K. G., (2004). Re-establishing livestock use on mined landscapes in the southern interior of BC, Available online: www.trcr.bc.ca/docs/2004-gizikoff.pdf.

Hill, C., (2003). Deloro mine site cleanup young's creek mine area rehabilitation alternatives final report, prepared for Ontario Ministry of the Environment, 107.

Hindle, J. P.; Grosskopf, T., (2000). Agricultural land classification study - Taree shire, report on methodology to accompany agricultural land classification map for Taree Shire, 17.

Hong, I. B.; Vogel, D. R., (1991). Data and model management in a genera1ized MCDM-DSS, Decision Sci., 22 (1), 1-25

Howat, D. R., (2000). Acceptable salinity, sodicity and pH values for Boreal forest reclamation, Alberta Environment, Environmental Sciences Division, Edmonton Alberta, ISBN 0-7785-1174-X (on-line edition), 191.

Joerin, F.; Theriault, M.; Musy, A., (2001). Using GIS and outranking multicriteria analysis for land use suitability assessment, Int. J. Geogr. Inf. Sci., 15 (2), 153-174

Messing, I.; Hoang, M. H., (2001). Using farmers’ knowledge for defining criteria for land qualities in biophysical land evaluation, Land Degrad. Dev., 12 (6), 541-553

Mu, Y., (2006). Developing a suitability index for residential land use: A case study in Dianchi drainage area. MS.c. thesis in Environmental Studies in Geography, Waterloo, Ontario, Canada.

Nijkamp, P., (1977). Stochastic quantitative and qualitative multicreteria analysis for environmental design, Pap. Reg. Sci. Assoc., 39 (1), 175-199.

Osanloo, M.; Akbari, A. D.; Hamidian, H., (2006). Selecting post mining land use through analytical hierarchy processing method: case study in Sungun copper open pit

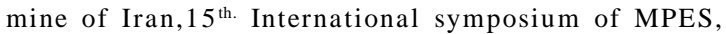
Torino, Italy

Osanloo, M.; Hekmat, A.; Aghajani Bazazi, A., (2006). Reclamation of granite stone quarry - A case study in Jostan granite mine, Tehran, Iran, $1^{\text {st. international }}$ seminar on mine closure, Perth, Australia

Paschke, M. W.; Redente, E. F.; Brown, S. L., (2003). Biology and establishment of mountain shrubs on mining disturbances in the Rocky mountains, Usa, Land Degrad. Dev., 14 (5), 459-480.

Roy, B., (1968). Classement et choix en présence de points de vue multiples (la méthode ELECTRE), RIRO, 8, 5775 .

Roy, B.; Skalka, J., (1984). ELECTRE IS: Aspects méthodologiques et guide d'utilisation, Document du LAMSADE,30, Université Paris Dauphine

Saaty, L. T., (1980). The analytical hierarchy process: Planning, priority setting. Resource allocation, McGraw Hill Company, New York. 
Saaty, L. T., (1990). The analytical hierarchy process, McGraw Hill. New York.

Soltanmohammadi, H.; Osanloo, M.; Aghajani, A., (2008). Developing a fifty-attribute framework for mined land suitability analysis using AHP-TOPSIS approach, post mining symposium, Nancy, France

Stellin, J. R.; Hennies, A.; Soares, L.; Fujimura, F.; Lauand, V., (2005). Area recovery project of dimension stone quarry mine, COMI and MPES, Banff, Alberta, Canada. 951-965.
Tafi, T. C.; Neuman, D.; Wraith, J.; Fedock, J., (2006). Reclamation effectiveness at three reclaimed abandoned mine sites in Jefferson County, Montana, Land Rehabilitation, Montana State University, Bozeman, Montana.

Uberman R.; Ostrêga, A., (2005). Applying the analytical hierarchy process in the revitalization of post mining regions, ISAHP 2005, Honolulu, Hawaii.

\section{AUTHOR (S) BIOSKETCHES}

Soltanmohammadi, H., B.Sc., M.Sc. is currently member of Kavoshgaran Consulting Engineers, Tehran, Iran. His research interests contain mined land suitability analysis, multi-criteria decision making and decision theory. Email: hsm_mine@yahoo.com

Osanloo, M., Professor in Geological Engineering (major) and Mining Engineering (minor) from University of Oklahoma, University of Amirkabir, Mining, Metallurgy and Petroleum Department of Iran. Tehran, Iran. Email:morteza.osanloo@gmail.com

Rezai, B., Professor in Mining Department of Amirkabir University of Technology in Tehran, Iran. He has published 160 articles in the field of mineral processing and mining engineering in journals and international symposiums. Email: rezai@aut.ac.ir

Aghajani Bazzazi, A., Ph.D. student in Mining Engineering Department of Amirkabir University of Technology and Faculty of Mining Engineering, Islamic Azad University, Savadkooh Branch, Iran. Email:abbas_aghajani_bazzazi@yahoo.com

\section{This article should be referenced as follows:}

Soltanmohammadi, H.; Osanloo, M.; Rezai, B.; Aghajani Bazzazi, A., (2008). Achieving to some outranking relationships between post mining land uses through mined land suitability analysis. Int. J. Environ. Sci. Tech., 5 (4), 535-546. 